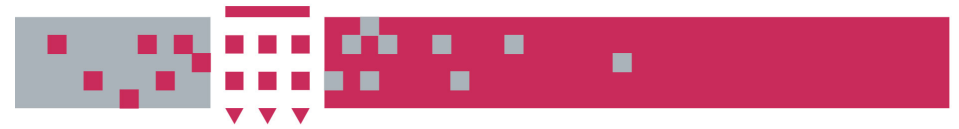

\title{
WestminsterResearch
}

http://www.wmin.ac.uk/westminsterresearch

\section{Electronic nose: clinical diagnosis based on soft computing methodologies.}

\author{
Vassilis Kodogiannis ${ }^{1}$ \\ Panagiotis Chountas ${ }^{1}$ \\ A.K. Pavlou ${ }^{2}$ \\ llias Petrounias ${ }^{3}$ \\ Hardial Chowdrey ${ }^{4}$ \\ Cecelia Temponi ${ }^{5}$ \\ ${ }^{1}$ Harrow School of Computer Science, University of Westminster \\ ${ }^{2}$ Cranfield Biotechnology Centre, Cranfield University \\ ${ }^{3}$ Department of Computation, UMIST \\ ${ }^{4}$ School of Biosciences, University of Westminster \\ ${ }^{5}$ School of Business, Southwest Texas State University
}

Copyright (C) [2002] IEEE. Reprinted from Proceedings of the IEEE International Symposium Intelligent Systems: Methodology, Models, Applications in Emerging Technologies IS2002, 10-12 Sept.2002, Varna, Bulgaria.

This material is posted here with permission of the IEEE. Such permission of the IEEE does not in any way imply IEEE endorsement of any of the University of Westminster's products or services. Internal or personal use of this material is permitted. However, permission to reprint/republish this material for advertising or promotional purposes or for creating new collective works for resale or redistribution must be obtained from the IEEE by writing to pubs-permissions@ieee.org. By choosing to view this document, you agree to all provisions of the copyright laws protecting it.

The WestminsterResearch online digital archive at the University of Westminster aims to make the research output of the University available to a wider audience. Copyright and Moral Rights remain with the authors and/or copyright owners. Users are permitted to download and/or print one copy for non-commercial private study or research. Further distribution and any use of material from within this archive for profit-making enterprises or for commercial gain is strictly forbidden.

Whilst further distribution of specific materials from within this archive is forbidden, you may freely distribute the URL of WestminsterResearch.

(http://www.wmin.ac.uk/westminsterresearch).

In case of abuse or copyright appearing without permission e-mail wattsn@wmin.ac.uk. 


\title{
Electronic Nose: Clinical Diagnosis based on Soft Computing Methodologies
}

\author{
V.S. Kodogiannis, P. Chountas, A. Pavlou, I. Petrounias, H.S.Chowdrey and C. Temponi
}

\begin{abstract}
Recently, the use of smell in clinical diagnosis has been rediscovered due to major advances in odour sensing technology and artificial intelligence. It was well known in the past that a number of infectious or metabolic diseases could liberate specific odours characteristic of the disease stage and among others, urine volatile compounds have been identified as possible diagnostic markers. A newly developed electronic nose based on chemoresistive sensors has been employed to identify in vitro 13 bacterial clinical isolates, collected from patients diagnosed with urinary tract infections, gastrointestinal and respiratory infections, and in vivo urine samples from patients with suspected uncomplicated UTI who were scheduled for microbiological analysis in a UK Health Laboratory environment. An intelligent model consisting of an odour generation mechanism, rapid volatile delivery and recovery system, and a classifier system based on a neural networks, genetic algorithms, and multivariate techniques such as principal components analysis and discriminant function analysis-cross validation. The experimental results confirm the validity of the presented methods.
\end{abstract}

Index Terms-Neural networks, Genetic algorithms, Electronic noses, Microbial analysis.

\section{INTRODUCTION}

There is increasing worldwide awareness that bionics and artificial intelligence (AI) will play an important role in many aspects of human activity. Medicine will be no exception, new socio-economical factors and the needs of an evolving global community are demanding the development and application of new intelligent diagnostic and therapeutic near-patient or home-based devices to control disease more effectively [1]. Advanced information technology and satellite communications combined with new intelligent sensors could result in the ability to monitor and control the worldwide spread of diseases like tuberculosis (TB), AIDS, cancer, metabolic diseases and

Dr. V.S. Kodogiannis and Mr. P. Chountas are with the Mechatronics Group, Computer Science Dept, Univ. of Westminster, London HAl 3TP, UK (telephone: +44-777-570976, e-mail: hodogiv(âwmin.ac.uk).

Mr. A. Pavlou was with Cranfield Biotechnology Centre, Cranfield University, Cranfield MK43 OAL, UK

Dr. I. Petrounias is with the Dept. of Computation, UMIST, PO Box 88, Manchester M60 1QD, UK (e-mail: ilias.petrouniasidco.umist.ac.uk).

Prof. H.S. Chowdrey is with Dept. of Biomedical Sciences, School of Biosciences, London WIW GUW (e-mail: h.s.chowdreyawmin.ac.uk)

Assoc. Prof. C. Temponi is with School of Business, Southwest Texas State University, San Marcos, TX 78666, USA, (e-mail: ct(01)(i)swt.edu). gastric disorders such as Helicobacter pylori (HP) infection [2]. Since the early report of an artificial electronic odour detection system by Persaud \& Dodd [3], a substantial amount of research has been targeted on the development of novel integrated gas-sensing systems. The potential applications for the Electronic Nose technology are very extensive. Those industries that are using or could use this technology include Food \& Drink, Chemical, Petrochemical, Packaging, Pharmaceutical, Flavours \& Fragrance, Environmental, Health and Security [4]. Over the past few years there have been an increasing number of attempts to apply artificial olfactory diagnostics in clinical practice [5]. The diagnosis of disease states is a primary pre-requisite of successful medical treatment and as such is a high priority in any area of clinical science. Microbial infections and related causes of illness seem to be one of the more common problems encountered in the world today and are widely reported by the press, especially when so-called "killer bugs" or "antibiotic-resistant" organisms are mentioned. In many cases, infection with micro-organisms produces a change in the smell of a person, which can be especially noticeable on the breath, in the urine or the stools. Such changes have been commonly used as an aid to diagnosis of disease and in some countries, smelling the patient or the body fluids of the patient was, and still is, an important tool in diagnosis. In 1986, National Geographic published an article on "The intimate sense of smell" in which the odour of different diseases was described and in which clinicians state that odour is important in diagnosis, especially in the emergency room.

However a critical step before introducing such "smart" devices into the clinic would be the in vitro static or dynamic headspace analysis of microbial volatile compounds, extracted from clinical isolates of UTI, HP and respiratory infections. A metabolite may be described as volatile if it is a gas or has a high vapour pressure under the environmental conditions in which it is liberated from a cell. Organic volatile compounds (VOCs) can affect all forms of life, from the pheromones of insects, the odours of plants, to putrefaction. Whether chemo-messengers intraspecies or interspecies (allelochemics), they form complex dynamic systems of odour mixtures which can affect species behaviour and adaptation. The following table presents some microbial volatiles and their biochemical precursors.

Detecting low numbers of bacterial species in clinical samples usually involves time consuming growth in selective media and subsequent isolation and identification by appropriate diagnostic procedures. Complex volatile mistures are released during bacterial interaction with the 
host tissue or media, and chromatographic techniques have been used in the past to characterise those species on their gas profiles [6]. Recently some novel biomedical, gassensing applications have been reported, such as the diagnosis of leg-ulcer streptococcal [7] and respiratory infections [8], detection of diabetes [9]. Gibson et al. [10] reported the characterisation of bacterial classes and growth phase prediction by applying sensor arrays combined with neural networks and other pattern recognition methods.

TABLE I

GENERATION OF MICROBIAL VOLATILES DUE TO METABOLIC REACTION WITH SPECIFIC BIOCHEMICAL PRECURSORS

\begin{tabular}{|c|c|c|}
\hline Bacterial species & Medium & Volatile Compound \\
\hline E. coli, Klebsiclla sp. & $\begin{array}{l}\text { Arabinose, } \\
\text { lactose }\end{array}$ & Ethanol \\
\hline $\begin{array}{l}\text { Proteus sp., Klebsiella sp, } \\
\text { Staph. Aureus, } \\
\text { Pseudomonas sp. }\end{array}$ & $\begin{array}{l}\text { Trypticase } \\
\text { soy broth }\end{array}$ & $\begin{array}{l}\text { Isobutanol, isopentyl } \\
\text { acetate ketones }\end{array}$ \\
\hline Proteus sp & L-methionine & $\begin{array}{l}\text { Dimethyl sulphide, } \\
\text { methyl mercaptan }\end{array}$ \\
\hline $\begin{array}{l}\text { Proteus sp, Enterococcus } \\
\text { sp. Klebsiella sp }\end{array}$ & Acatyleholine & $\begin{array}{l}\text { Trimethylamine, ethyl } \\
\text { acetate }\end{array}$ \\
\hline Proteus sp, C. septicum & $\begin{array}{l}\text { Broth } \\
\text { (complex) }\end{array}$ & $\begin{array}{l}\text { Isobutylamine, } \\
\text { isopentylamine, } \\
\text { ethylamine }\end{array}$ \\
\hline Proteus sp & $\begin{array}{l}\text { Phenylalanine } \\
\text {, valine } \\
\text { leucine }\end{array}$ & $\begin{array}{l}\text { Benzaldehyde, } \\
\text { isobutyraldehyde } \\
\text { isovelaraldehyde }\end{array}$ \\
\hline P. aeruginosa & $\begin{array}{l}\text { Broth } \\
\text { (complex) }\end{array}$ & $\begin{array}{l}\text { Butanol, methyl ketones, } \\
\text { 2-heptanone }\end{array}$ \\
\hline
\end{tabular}

Recently, a rapid detection of Helicobacter pylori and gastroesophageal clinical isolates employing a wide range of metal oxide and conducting polymer sensors combined with neural networks (NNs) and multivariate techniques as been reported [11].

The objectives of this study are to:

- Introduce the application of a newly devcloped intelligent gas-sensing device in a UK Public Health Laboratory environment;

- Analyse 45 specimens of human urine by the application of an intelligent diagnostic model based on novel generation, detection, and rapid recognition of urinary volatile patterns within 5 hrs of receipt of specimens in the laboratory.

- Discriminate in vitro, between 13 bacterial clinical isolates all collected from patients diagnosed with Urinary Tract infections (UTI), gastrointestinal and respiratory infections

- Combine classical NN techniques with advanced AI-based methodologies (GA) to generate a powerful hybrid classification tool; demonstrate the power of a GA, by which a sophisticated NN can be trained for improved generalisation and classification performance;

- Adopt a soft fusion of the outputs of multiple classifiers dedicated to specific feature parameters.

\section{EXPERIMENTAL}

\section{A. Volatile sensing system}

A gas sensor array (Bloodhound Sensors) cmployed 14 electroconductive polymer, semi-micro, chemoresistors produced by electropolymerisation of the corresponding monomers directly onto the sensor surface. Production of sensors primarily involved doped polypyrroles, polythiophenes and polyanilines with different substitute groups in the polymer structure as illustrated in Fig. 1. The sensor array was also mounted in solenoid valves, which provided the headspace sample with carbon-activated filtered clean airflow of $4 \mathrm{ml} \mathrm{sec}{ }^{-1}$. Specific selection and polymer tailoring, doping materials and precise manufacturing process can make each of the 14 sensors consistently responsive to a variety of volatile mixtures.

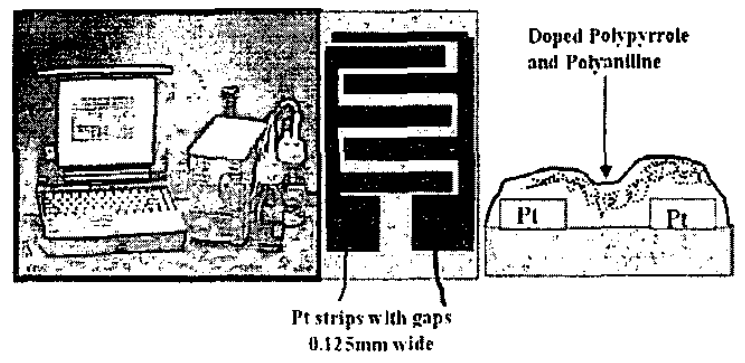

Fig. 1: The Bloodhound gas-sensing unit

The sensor electrodes used were manufactured photolithogra-phically and consisted of a gold interdigitated structure on aluminum substrate with a titanium adhesion layer. Electropolymerisation was carried out by electrode immersion in aqueous or acetonitrile solutions of the monomer and cycling between $-0.1 \mathrm{~V}$ and $+0.8 \mathrm{~V}$ or $+1.7 \mathrm{~V}$ for thiophenes. Teflon upgraded flow cells prevented volatile adsorption onto the housing surfaces. The sensory unit employs a control sample system that generates two calibration points:

- A sensor baseline, which is generated by continuous flow of activated carbon filtered air passing over sensor surfaces and

- A control-sample unit that contains $100 \mathrm{ml}$ of sterile water, able to perform a flush-cycle and define a standard reference point.

A specific sampling profile consisted of $5 \mathrm{~s}$ of absorption time and $16 \mathrm{~s}$ of desorption time was applied and controlled by specially designed data capture software.

\section{B. In vitro classification of bacterial clinical isolates}

The following bacterial species, as illustrated in Table II, were isolated from patients suffering from Septicaemia, Respiratory, wound and Urinary Tract infections (UTI). After primary culture and biochemical profiling and characterisation they were assigned a Gloucestershire Royal Hospital culture collection number.

\section{1) Bacterial volatile generation}

The above clinical isolates were recovered on Blood agar plates No.2 (Oxoid), containing 5\% sterile horse-blood (Oxoid) for $16 \mathrm{hrs}$ following primary isolation, and successful growth the biochemical profiles of all species were identified using conventional microbiological analysis performed at Gloucestershire Public Health laboratory (UK). Each one of the bacterial species was inoculated $\left(10^{6}\right.$ $\mathrm{CFU}$ ) on blood agar No 2 (Oxoid) containing 5\% horse- 
blood (Oxoid), urea (lmg ml-1), lactose $\left(2 \mathrm{mg} \mathrm{ml}^{-1)}\right.$, Lmethionine, L-valine and L-leucine $\left(0.5 \mathrm{mg} \mathrm{ml}^{-1}\right.$, Sigma) adjusted at $\mathrm{pH} 7.3$.

TABLE II

GENERAI AND BIOCHEMICAL CHARACTERISTICS OF 13 CLINICAL ISOLATES

\begin{tabular}{|c|c|c|c|c|}
\hline Speciss & $\begin{array}{l}\text { How .No } \\
\text { GRH PHLS) }\end{array}$ & Source & $\begin{array}{l}\text { Dignosid } \\
\text { condition }\end{array}$ & Blectemical characteristics \\
\hline Escherickiacoli & 72999 & Unine & UT! & 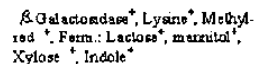 \\
\hline Citrabater ipp. & 94513 & Bload & Sopticatemis & 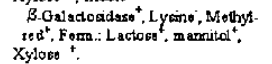 \\
\hline B)terdacter cloacae & 93986 & Foeces & $\begin{array}{l}\text { Nosocomist } \\
\text { UTI }\end{array}$ & 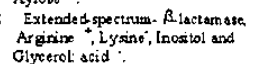 \\
\hline Breyococausforcabs & 72971 & Utine & tut & 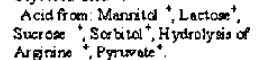 \\
\hline Extrococas spp. & 93981 & $\begin{array}{l}\text { Urinel } \\
\text { fatces }\end{array}$ & Cyestits & Pyrusalo; ; mebcioset. \\
\hline Netorella orytoca & 94022 & Uno & UTI & 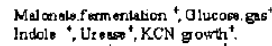 \\
\hline 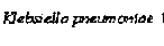 & e 167913 & Sputum & Pneum aria & 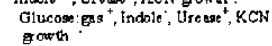 \\
\hline Latchaxilks spp. & 71855 & $\begin{array}{l}\text { Gestric } \\
\text { Juce }\end{array}$ & $\begin{array}{l}\text { Castric } \\
\text { cancer }\end{array}$ & Catdase ; $\mathrm{H}_{2} \mathrm{Sg}$. \\
\hline Protes spp. & 94488 & $\mathrm{U} \sin$ & $\begin{array}{l}\text { Bladder } \\
\text { Infection }\end{array}$ & 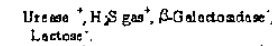 \\
\hline Pretas marditis & 94402 & Usine & UTI & Urease "Orrithino decarborzlase". \\
\hline Saftylococew aurews & 94707 & Warid & Skin lesion & Catalase ", Cotgulase", \\
\hline Pseasiomonas serugros & mosa 73021 & Sputum & Chestiffection & Oxidos ${ }^{+}$. Gelatinase ${ }^{*}, \mathrm{NH}_{3}$ \\
\hline Strepteroscus pyozenes & Jes $94 \pi 7$ & Throet sma & ab Sore throat & $\begin{array}{l}\text { RHaemolys is , G tous A } \\
\text { Ferm.: Lectose }\end{array}$ \\
\hline
\end{tabular}

All bacterial cultures were incubated at $37^{\circ} \mathrm{C}$ aerobically for approximately $12 \mathrm{hrs}$ except Lactobacillus spp. that was cultured micro-aerobically at $45^{\circ} \mathrm{C}$ and $\mathrm{pH} 6.0$. A number of controls containing only sterile cultures were also incubated for the same period of time in order to study the difference between actual bacterial volatile patterns and "noisy" background produced by humidity, sensor aging and natural enzymatic digestion of cultural substrates.

\section{2) Volatile delivery system}

Following $12 \mathrm{hrs}$ of incubation at $37^{\circ} \mathrm{C}$, each of the growing cultures-measured at the stationary phase-were placed into 21 polypropylene Mylar bags and inflated with carbonactivated filtered clean air (Hepavent, Whatman).

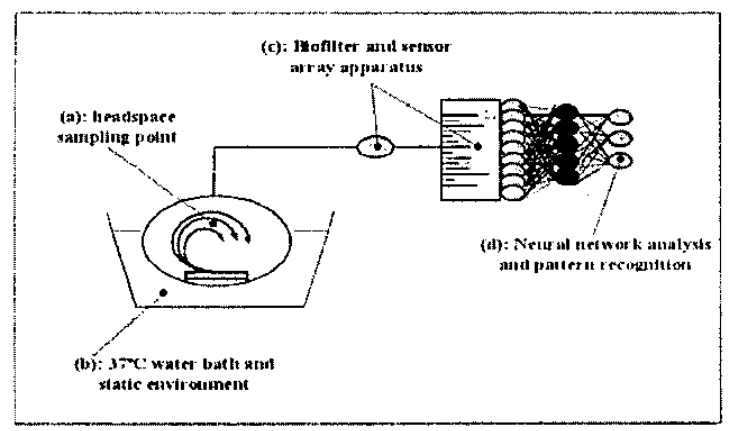

Fig. 2: Schematic representation of experimental apparatus

Each bag was transferred into a $37^{\circ} \mathrm{C}$ water bath and left to equilibrate for $5 \mathrm{~min}$ before being connected with the sensory unit through a $15 \mathrm{~cm}$ long Teflon tubing, a hydrophobic PTFE filter (Hepavent, Whatman), to ensure a sterile less humid environment over the sensor surfaces.
The sampling point was adjusted to a set height above the static headspace as illustrated in Fig. 2. A flow rate of $200 \mathrm{ml} \mathrm{min}^{-1}$ was set automatically by data control software. Additionally environmental conditions at the sampling point, inside the water bath were continuously monitored in order to establish a standardised sampling protocol.

\section{3) Bacterial pattern recognition}

Fig. 3 displays a real time sensory response analysed by 5 extracted sensor features that describe sensor-volatile physicochemical interaction and pattern extraction: (a) Divergence: maximum step response, (b) Absorption: maximum rate of change of resistance), (c) Desorption: maximum negative rate of change of resistance, (d) Area under the curve and (e) Ratio Absorption/Desorption. In order to improve the bacterial classification process fourteen conducting polymers and the above 5 features generated a set of 70 sensor parameters. All sensors responses were pre-processed by using a suitable normalisation algorithm [12].

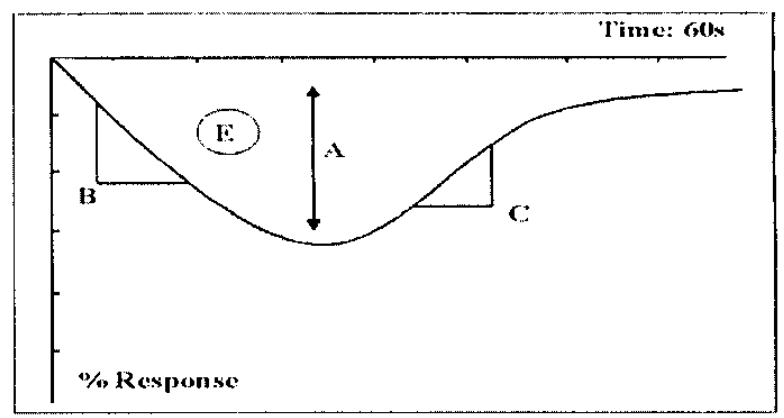

Fig. 3: Parameters measured for each sensor response

\section{In vivo classification of Urinary tract infections}

UTI is a significant cause of morbidity with 3 million UTI cases each in the USA alone [13]. Thirty-one percent of nosocomial infections in medical intensive care units are attributable to UTI, and it is estimated that $20 \%$ percent of females, aged of 20 and 65 years suffer at least one episode per year. There are also links to other complicated or chronic urological disorders such as pyelonephritis, urethritis, and prostatitis[14]. Approximately $80 \%$ of uncomplicated UTI are caused by E.coli and $20 \%$ by enteric pathogens such as Enterococci, Klebsiellae, Proteus $s p$, coagulase (-) Staphylococci and fungal opportunistic pathogens such as Candida albicans [15]. Current diagnostic techniques require 24-48 hrs to identify pathogenic species in urine midstream specimens $\left(\geq 10^{5} \mathrm{c}\right.$ $\mathrm{ml}^{-1}$ ) and apply antibiotic sensitivity tests. Despite the introduction of molecular tests, microscopy and culture remain the gold standard in every day clinical practice.

1) Urine samples and volatile generating kits (VGK) Forty-five $5 \mathrm{ml}$ urine samples (following eukaryotic cell filtering extraction) were collected from randomly selected patients admitted in Gloucestershire PHLS and inoculated into specially made centrifuge bottles $(50 \mathrm{ml}$, Sterilin) each containing $95 \%$ BHI broth (Oxoid), 5\% serum bovine (Oxoid), $0.70 \mathrm{mg} \mathrm{ml}^{-1}$ of a series of amino acids (L-Leucine, 
L-Alanine, L-Serine, L-Valine, L-Asparagine, LGlutamine, L-Methionine, Sigma), $1 \mathrm{mg} \mathrm{ml}^{-1}$ Urea (Sigma), $0.75 \mathrm{mg} \mathrm{ml}^{-1}$ Lactose (Sigma), $0.1 \mathrm{mg} \mathrm{ml}^{-1}$ Casein (Oxoid), $0.3 \mathrm{mg} \mathrm{ml}^{-1}$ Acetylcholine (Sigma) to a final volume of $20 \mathrm{ml}$ per VGK and incubated aerobically for $5 \mathrm{hrs}$ at $37^{\circ} \mathrm{C}$.

2) Flow injection analysis (FIA) of urinary volatiles After $5 \mathrm{hrs}$ of incubation to coincide with the logarithmic phase of growth, $45 \mathrm{VGK}$ were placed in a $37^{\circ} \mathrm{C}$ water bath and directly connected with a specifically designed airfiltered sparging (bubbling) system. This consisted of Teflon tubing (Tygon), a hydrophobic biofilter $(0.45 \mu \mathrm{m}$ PTFE, Whatman-Hepavent) and an activated carbon filter (Whatman) to provide clean air-flow above the urine headspace. A flow rate of $200 \mathrm{ml} \mathrm{min}^{-1}$ was set automatically and environmental conditions at the sampling point were continuously monitored. The actual urine sampling time and baseline recovery per specimen was 3 $\min$.

\section{3) Intelligent UTI pattern recognition system}

Thirty cases of UTI were identified from 45 randomly selected samples by standard microscopy and culture: 13 patients were infected with E.coli (e), 9 with Proteus sp. (p) and 8 with coagulase (-) Staphylococcus sp., (st). Two genetic training algorithms processed urine data through a parallel evolutionary succession process towards competent $\mathrm{NN}$ solutions. The first GA analysed patient data that had been randomly divided into a "training" group of 31 urinary samples (e: $9, \mathrm{p}: 6$, st: 5 and $\mathrm{n}: 11$ ) and a group of 14 "unknowns" (c: 4, p: 3 , st: 3 and n: $4,31 \%$ of patient collected data).

\section{ODOUR RECOGNITION AND DATA ANALYSIS}

\section{A. In vitro analysis}

Two hundred and forty-eight bacterial patterns of 14 classes and 70 normalised sensor parameters constructed a matrix of 17,360 sensor data-items that was analysed by an intelligent system consisting of Radial Basis Function Networks (RBF). Overall, the sensor data matrix was randomly divided into a training group containing 200 bacterial patterns and a testing one of 48 random "unknown" samples.

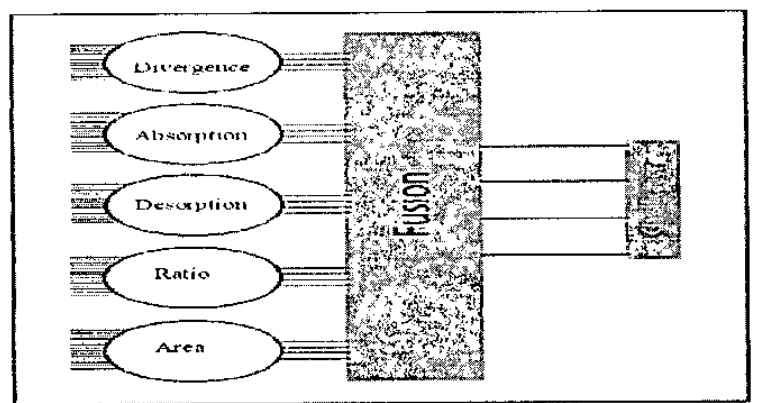

Fig. 4: Multiple Classifier Architecture

Recently, the concept of combining multiple networks has been actively exploited for developing highly reliable neural network systems. One of the key issues of this approach is how to combine the results of the various networks to give the best estimate of the optimal result. A straightforward approach is to decompose the problem into manageable ones for several different sub-networks and combine them via a gating network. The proposed architecture is a neural network system containing five parallel modules, one for each of the bacterial properties as shown in Fig. 4. Each network module makes a classification from a single property and their results are combined, using an averaging approach, to make an overall classification. All modules contain fourteen input nodes and four output nodes. The fourteen input nodes correspond to the fourteen sensor parameters.

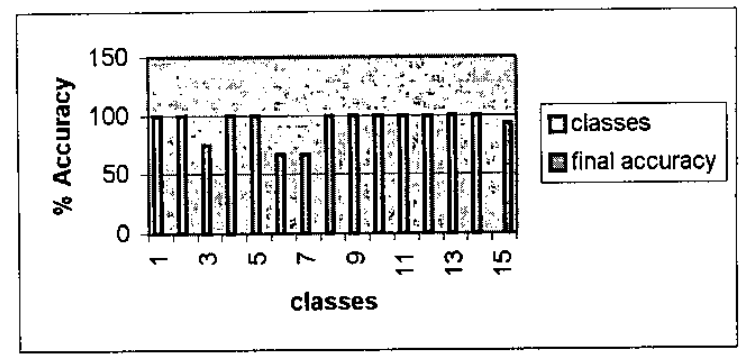

Fig. 5: Fusion analysis results

The four output nodes are sufficient for binary representation of the fourteen classes (13 bacterial classes and the control group). Four binary digits can represent sixteen integers, so each class is assigned one of fourteen binary patterns. Two patterns remained unused. The soft combination of neural classifiers resulted in $93.75 \%$ accuracy over the testing dataset, demonstrating in this way the efficiency of this scheme in terms of accuracy and processing-time. The relevant results are illustrated in Fig. 5.

\section{B. In vivo analysis}

An evolutionary process of 5 generations ( $3 \mathrm{NNs} /$ generation) was carried out employing 1 crossover and a mutation rate of 0.5 . Additionally the second GA performed a much broader evolutionary optimisation analysis of 100 generations. It also attempted to analyse the same amount of patient data but with a higher ratio of "unknown" proportion ( $42 \%$ of collected patient data) including 26 training samples (e: 8, p: 4 , st: 4, n: 10 ) and 19 "unknown" UTT (e:5, p:5, st:4, n:5). A population of 600 NNs was evolved using an immigration mode, 2 crossovers and a mutation rate of 0.7 towards the "fittest" NN solution.

Both "genetically" selected sensor parameters were àlso used to perform PCA and DFA-cv. PCA accomplished non-parametrically a significant dimension reduction by minimising minor UTI data variations so that information could be depicted on a few two-dimensional principal component score plots. Two parallel evolutionary algorithms selected $2 \mathrm{NN}$ solutions. The first was a 3-layer (28-12-4) back-propagation $\mathrm{NN}$ that used an adaptive learning rate, a momentum of 0.42 , an input pattern noise of 0.03 and achieved a $98 \%$ prediction rate. Thirteen out of 14 "unknown" UTI samples were identified correctly with 
a prediction output confidence ranging from 0.75 to 1.01 . The intelligent system failed to characterise only one urine sample previously diagnosed with E.coli infection.

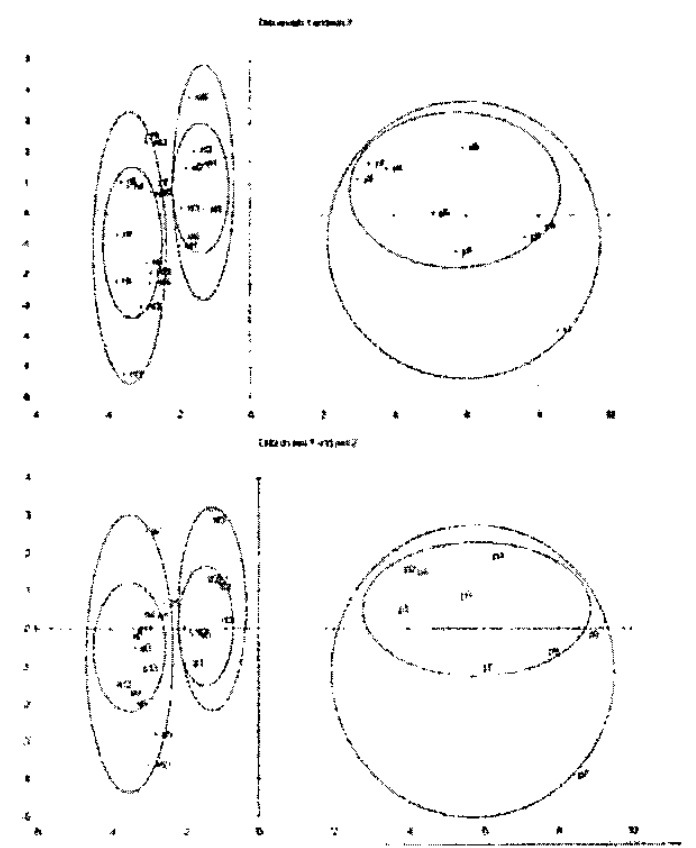

Fig. 6: Extraction of "genetically" selected sensor parameters and twodimensional representations of PCA clustering between: a. normal urine (n), Proteus sp. (p) and Staphylococcus sp. (st) and b: E.coli (e), Proteus sp. (p) and Staphylococcus sp. (st). (Inner and outer circles divide most closely linearly discriminated patterns from the most drifted ones, respectively).

However, this single pattern confusion was limited to the case of distinguishing between E.coli infection and normal urine. Both their prediction confidence outputs were very close- 0.37 for E. coli and 0.43 for normal urine- but below a 0.5 test tolerance limit.

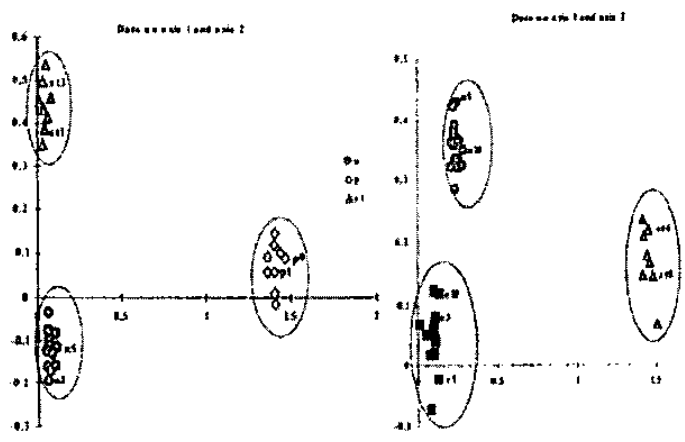

Fig. 7: DFA and 3-group separation between: a. normal urine (n), Proteus sp. (p) and Staphylococcus sp. (st) and b. normal urine, E.coli (e) and Staphylococcus sp.

Twenty-eight "genetically" selected parameters performed PCA and DFA, which displayed two graphical cluster separations between Proteus sp., Staphylococcus sp. UTI and normal samples. Cross-validation reclassified correctly 6 "unknown" patient samples (Figs 6a \& 7a). Furthermore by extracting all "genetically" selected sensor parameters that had been previously used as input neurones it was possible to reveal hidden non-linear patterns characteristic of each UTI group. Furthermore the second 3-layer NN (22-15-4) achieved a $95 \%$ prediction rate and recognised 18 out 19 "unknown" UTI cases. Only one normal patient sample had been mistaken for E.coli infection.

A two-dimensional discrimination plot between 3 of the tested UTI groups (e, st, p) was produced by PCA. DFA also separated patient samples infected with E.coli, Staphylococcus sp. and normal urine samples. Cross validation recognised 7 "unknown" UTI cases (Figs $6 \mathrm{~b} \&$ 7b).

\section{CONCLUSIONS}

In recent years, antibiotic resistance and the evolutionary emergence of "super bugs" are considered some of the most significant causes of nosocomial infections and have increasingly severe biological, health and economic impact. Conventional diagnostic microbiology requires $24-48 \mathrm{hrs}$ to identify each pathogenic species and perform antibiotic sensitivity tests by employing the expertise of skilled personnel, adding significantly to total health care cost. There is need for innovative inexpensive tests to be developed for early diagnosis of infectious diseases and control of antibiotic resistance. The recent use of GC-MS or MS methods accompanied by $\mathrm{NN}$ and multivariate analysis although are considered very sensitive, they need highly skilled personnel and are characterised by increasing capital cost. Intelligent gas sensor technology has been applied in several research areas, including biomedicine. Many research groups around the world are actively developing new improved gas sensors with broad sensitivities to certain classes of volatile organic compounds. As these sensors become commercially viable, the EN might well achieve higher levels of acceptance in medical applications.

The present system resulted in the delivery of bacterial odours in the form of repetitive 'sniffs', and achieved higher control by keeping the sampling point, the headspace and liquid volumes constant. Additionally there was continuous monitoring of environmental conditions at the sampling point. There are several advantages in the application of $\mathrm{NN}$ models as opposed to other statistical techniques. Their ability to generalise is particularly useful since rough data is often noisy due to some sensor drift. Selecting and constructing the right learning data (input) is crucial in pattern recognition methods. Each class must be composed of representative and reproducible samples. The quantity of these samples does not increase the discrimination confidence instead it is the "quality" of representation carried in each input sample that determines pattern recognition performance. The applied GA-NN technique achieved a high prediction rate and enabled the parallel use of multivariate techniques too, showing a degree of correlation among genetically selected input parameters. The present work proposes a novel application of GA-NN in combination with multivariate techniques in bacterial class discrimination. However, the use of multiple $\mathrm{NN}$ fusion is a challenging and more promising approach. The adopted parallel architecture reduces the 
dimensionality of the network search space thus increasing both computational efficiency and the probability that optimal network parameters will be found within the search space. Future work will investigate the integration of GAs to the multiple classifier scheme employed however with a more accurate fusion decision criterion, such as the fuzzy integral.

\section{REFERENCES}

[1] A.M. Flynn, K.R. Udayakumar, D.S. Barrett, J.D. McLurkin, D.L. Franck, A.N. Shectman, "Tomorrow's surgery: micromotors and microrobots for minimally invasive procedures," Minimally Invasive Therapy and Allied Technologies, vol. 7, no. 4. pp. 343-352, 1998.

[2] Gibson. T.D., Hulbert, J.N, Prosser, O.C., Pavlou A.K, "Not to be sniffed at", Microbiology Today, vol. 27, No. 1, pp. 14-17, 2000.

[3] Persaud, K., Dodd, G.H., "Analysis of discrimination mechanisms of the mammalian olfactory system using a model nose", Nature, Vol. 299 , pp. 352-355 1982.

[4] Gopel, W., "Chemical Imaging: I. Concepts and Visions for Electronic and Bioelectronic Noses", Sensors \& Actuators B, Vol. 52, pp. 125-142, 1998

[5] Gardner, J.W., Shin, H.W., Hines, E.L., "An electronic nose system to diagnose illness", Sensors \& Actuators B , Vol. 70, pp. 19-24, 2000.

[6] Cox, C.D., Parker, J., "Use of 2-aminoacetophenone production in identification of Pseudomonas aeruginosa". J. of Clinical Microbiology, Vol. 9, pp. 479-484, 1979.

[7] Parry, A.D., "Leg ulcer odour detection identifies b-haemolytic streptococcal infection", $J$ Wound Care, Vol. 4, pp. 404, 1995

[8] Hanson III, C.W., Steinberger H.A., "The use of a novel electronic nose to diagnose the presence of intrapulmonary infection", Anaesthesiology, Vol. 87, No. 3A, pp. 269, 1997

[9] Wang, P., "A novel method for diabetes diagnosis based on electronic noses", Bios. \& Bioelectronics, Vol. 12, pp. 1031-1036, 1997

[10] Gibson, T.D., Hulbert, J.N, Prosser, O.C, "Detection and simultaneous identification of micro-organisms from headspace samples using an electronic nose", Sensors \& Actuators B, Vol. 44, pp. 413-422, 1997

[11] Pavlou, A.K., Magan, N., Sharp, D., Brown, J., Barr, H., Turner, A.P.F., "An intelligent rapid odour recognition model in discrimination of Helicobacter pylori and other gastroesophageal isolates in vitro", Biosensors \& Bioelectronics, Vol. 15, pp. 333-342, 2000

[12] A.K. Pavlou, V.S. Kodogiannis, A.P.F. Tumer. "Intelligent classification of bacterial clinical isolates in vitro, using electronic noses", Int. Conf. on Neural Networks and Expert Systems in Medicine and HealthCare, Greece, pp. 231-237, 2001.

[13] Schaechter M, Medoff G, Eisenstein BI, eds. Mechanisms of microbial disease, $2^{\text {nd }}$ edn. Baltimore: Williams \& Wilkins, 1993.

[14] Lipsky BA. "Prostatitis and urinary tract infection in men: what's new; what's true?", Am J Med, Vol. 106, pp. 327-34, 1999.

[15] Honkinen O, Lehtonen OP, Ruuskanen O, Huovinen P, Mertsola J "Cohort study of bacterial species causing urinary tract infection and urinary tract abnormalities in children", BMJ, Vol. 318, pp. 770-71, 1999. 